\title{
EiFPSUK \\ Reconstruction of full thickness nasal defects following resection of skin malignancies and trauma: A single surgeon's experience.
}

Mr. Baskaran Ranganathan and Prof. Tim Woolford

Manchester Royal Infirmary

\section{Background}

Reconstruction of full thickness nasal defect following excision of skin malignancies or post traumatic nasal deformity is challenging and often requires multi-staged reconstructive procedures. Optimum aesthetic and functional results of the nose could be achieved by reconstructing each layers of nasal wall (skin, cartilage and mucosa) with like for like tissues.

\section{Objective:}

To evaluate the choice of nasal reconstruction techniques used for different subunit defects and outcomes of the surgery including complications.

\section{Methodology}

Prospectively collected data was analysed for 64 patients operated between 2005 and 2017 with age ranging from 27 to 86 years (mean 63 years, Male-35, Female- 29) with a minimum follow up period of 6 months.

\section{Results:}

Three-layer staged reconstruction with interpolated flaps (Paramedian forehead flap or melolabial flap) conchal cartilage and septal mucosa (mucosal advancement or Hinge flap) was used. In non-cancer cases with full thickness defect involving lower third nose, adjacent skin from residual nose is turned down to form a inner lining ('Turned down flap').

\begin{tabular}{|l|r|c|}
\hline \multicolumn{1}{|c|}{$\begin{array}{c}\text { Type of flap + Conchal } \\
\text { cartilage }\end{array}$} & Inner lining & Subunit defect \\
\hline $\begin{array}{l}\text { Melo-labial flap } \\
(\mathbf{n}=\mathbf{6})\end{array}$ & Hinge flap- 1 & Alar +/- partial tip defect \\
\hline $\begin{array}{l}\text { Paramedian forehead flap } \\
(\mathbf{n}=58)\end{array}$ & Hinge flap- 29 & Alar, tip, side wall and \\
\hline & $\begin{array}{r}\text { Mucosal advancement- } 23 \\
\text { Split thickness skin- } 5\end{array}$ & dorsum defect \\
\hline & Primary closure- 1 & \\
\hline
\end{tabular}

Four patients had partial flap failure and one required return to theatre to control bleeding.
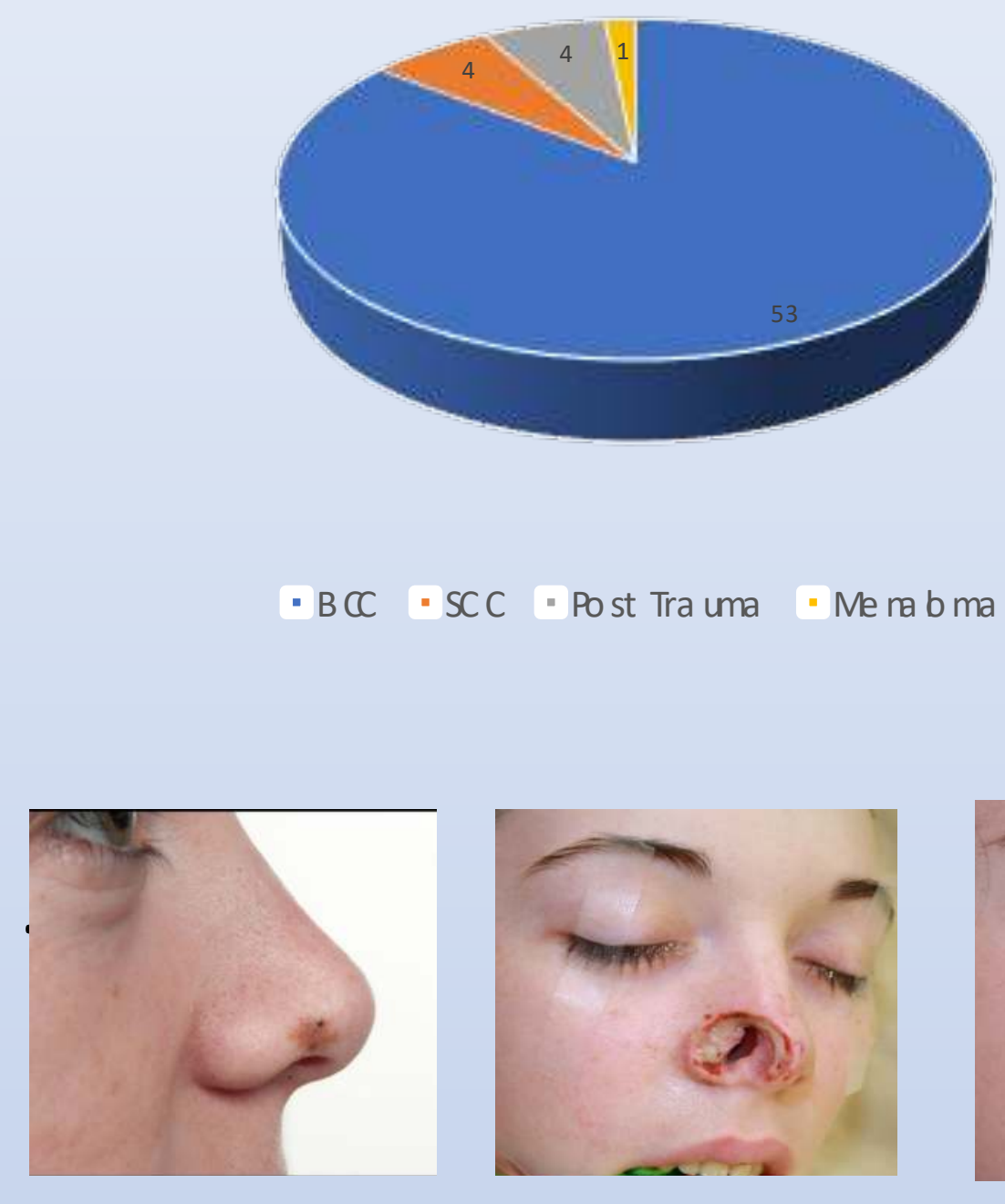

- B C - SCC - Post Tra uma = Merabma
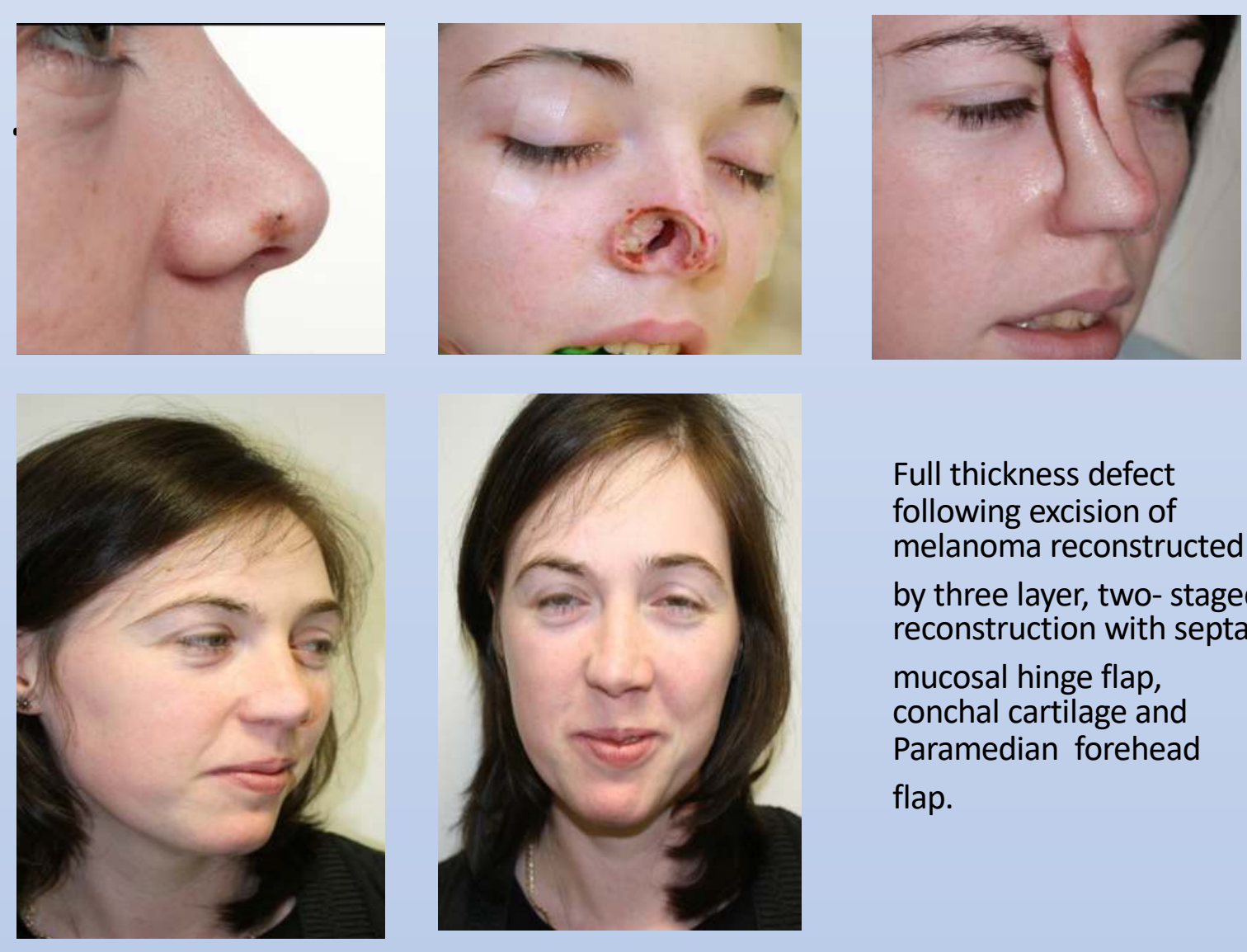

Full thickness defect following excision of melanoma reconstructed by three layer, two- staged reconstruction with septal mucosal hinge flap, conchal cartilage and Paramedian forehead flap.

\section{Discussion:}

The principles of nasal reconstruction include restoration of function and to provide an aesthetically acceptable contour of the nose. Each nasal defect should be carefully assessed in relation to its thickness and nasal subunits involved, and reconstruction should be tailored to the individual depending on the availability of the tissues, patient expectation and their fitness for surgery.

\section{Conclusion:}

A vascularised interpolated pedicle flap with a three-layer reconstruction is an effective technique to reconstruct as full thickness nasal defect. 